https://doi.org/10.21516/2072-0076-2021-14-1-89-95

\title{
Препериметрическая глаукома
}

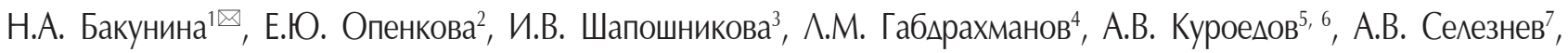
A.E. Заргарян ${ }^{8}$

${ }^{1}$ ГКБ № 1 им. Н.И. Пирогова, Ленинский проспект, д. 8, Москва, 119049, Россия

${ }^{2}$ МАУЗ ОЗП ГКБ № 8, ул. Горького, Д. 28, Челябинск, 454071, Россия

${ }^{3}$ ООО «ОЦ "Хорошее зрение"», ул. Рукавишникова, д. 20, Кемерово, 650000, Россия

4 ГБУЗ СОКОБ им. Т.И. Ерошевского, ул. Ново-Садовая, д. 158, Самара, 443068, Россия

${ }_{5}^{5}$ ФКУ «ЦВКГ им. П.В. Мандрыка», ул. Б. Оленья, д. 8а, Москва, 107014, Россия

${ }^{6}$ ФГАОУ ВО «РНИМУ им. Н.И. Пирогова» Минздрава России, ул. Островитянова, д. 1, Москва, 117997, Россия

7 ФГБОУ ВО «ИвГМА» Минздрава РФ, Шереметевский просп., д. 8, Иваново, 153012, Россия

${ }^{8}$ Офтальмологическая клиника «Доктор Глазов», ул. Пролетарская, д. 7, Балашиха, 143980, Россия

В последнее время в офтальмологической литературе встречается много информации, касающейся вопросов диагностики препериметрической глаукомы (ППГ), однако алгоритмы выявления первичной открытоугольной глаукомы (ПОУГ) на данном этапе болезни еще не разработаны и нет единого мнения о том, какие же параметры и методы рекомендуется использовать. В предлагаемом обзоре обобщены имеющиеся в литературе сведения о диагностике ППГ и выделены основные параметры, на которые следует обращать внимание при обследовании пациентов с ПОУГ на ранней допериметрической стадии.

Ключевые слова: препериметрическая глаукома; оптическая когерентная томография; периметрия; комплекс ганглиозных клеток сетчатки; слой нервных волокон сетчатки; внутренний плексиформный слой

Конфликт интересов: отсутствует.

Прозрачность финансовой деятельности: никто из авторов не имеет финансовой заинтересованности в представленных материалах и методах.

Для цитирования: Бакунина Н.А., Опенкова Е.Ю., Шапошникова И.В., Габдрахманов Л.М., Куроедов А.В., Селезнев А.В., Заргарян А.Е. Препериметрическая глаукома. Российский офтальмологический журнал. 2021 ; 14 (1): 89-95. https://doi. org/10.21516/2072-0076-2021-14-1-89-95

\section{Preperimetric glaucoma}

Natalia A. Bakunina ${ }^{1 凶}$, Elena Y. Openkova², Irina V. Shaposhnikova33, Lenar M. Gabdrakhmanov ${ }^{4}$ Alexandr V. Kuroyedov ${ }^{5,6}$, Aleksei V. Seleznev7, Hasmik Y. Zargaryan ${ }^{8}$

${ }^{1}$ N.I. Pirogov City clinical hospital N 1, 8, Leninsky prospect, Moscow, 119049, Russia

${ }^{2}$ Municipal Autonomous health institution "City Clinical Hospital N 8", 28, Gor'kogo St., Chelyabinsk, 454071, Russia

${ }^{3}$ Good Vision Center, 20, Rukavishnikova St., Kemerovo, 650000, Russia

${ }^{4}$ Samara T.I. Eroshevsky Regional Clinical Ophthalmological Hospital, 158, Novo-Sadovaya St., Samara, 443068, Russia

${ }^{5}$ Mandryka Central Clinical Hospital, 8A, Bolshaya, Olen'ya St., 107014, Moscow, Russia

${ }^{6}$ N.I. Pirogov Russian National Research Medical University, 1, Ostrovityanova St., 117997 Moscow, Russia

${ }^{7}$ State Medical Academy, 8, Sheremetevsky Prospekt., 153012, Ivanovo, Russia

${ }^{8}$ Doctor Glazov Ophthalmology Clinic, 7, Proletarskaya St., 143980, Balashikha, Russia nata-oko@mail.ru

Recently, much literature data is available on the issue of diagnosis of preperimetric glaucoma (PPG), but no recognized algorithms of detecting primary open-angle glaucoma (POAG) at this stage have been developed, and there is no general opinion as to what parameters and techniques should be used. The review offers a generalization of the literature data on PPG diagnosing and specifies the main parameters that should be taken into account in testing POAG patients at the early preperimetric stage. As is known, the diagnosis of glaucoma is based 
on detectable changes in the optic nerve head and visual field, but the onset of the disease occurs long before the above changes. Currently, the approach shifts towards early OCT diagnosis of glaucoma. Cohort studies show that structural disorders are detected 5-12 years earlier than functional ones in 17-60\% patients with POAG.

Keywords: preperimetric glaucoma; optical coherence tomography; perimetry; retinal ganglion cell complex; retinal nerve fiber layer; internal plexiform layer

Conflict of interests: there is no conflict of interests.

Financial disclosure: No author has a financial or property interest in any material or method mentioned.

For citation: Bakunina N.A., Openkova E.Y., Shaposhnikova I.V., Gabdrakhmanov L.M., Kuroyedov A.V., Seleznev A.V., Zargaryan H.Y. Preperimetric glaucoma. Russian ophthalmological journal. 2021; 14 (1): 89-95 (In Russian). https://doi.org/10.21516/2072-00762021-14-1-89-95

Основными причинами повышения показателя заболеваемости первичной открытоугольной глаукомой (ПОУГ) являются ее бессимптомное течение и сложность диагностики на начальных стадиях [1]. В связи с этим актуальной остается проблема выявления ранних признаков ПОУГ, предшествующих развитию выраженной глаукомной оптиконейропатии (ГОН).

Долгое время золотым стандартом диагностики глаукомы считалась стандартная автоматизированная периметрия (САП) - Humphrey Field Analyser (HFA) [2]. В связи с этим, как правило, ПОУГ выявляют только при характерном изменении поля зрения (ПЗ). В настоящее время с помощью новейшего оборудования, такого как оптический когерентный томограф (ОКТ) и сканирующий лазерный поляриметр, ранние структурные изменения диска зрительного нерва (ДЗН) при ПОУГ возможно обнаружить еще до ухудшения ПЗ.

Когортные исследования показывают, что у 17-60 \% пациентов с ПОУГ структурные нарушения (повреждения ганглиозных клеток сетчатки, ГКС) обнаруживаются на 5-12 лет раньше, чем функциональные (характерные для глаукомы дефекты П3) [3, 4]. Поэтому большая часть пациентов с препериметрической глаукомой (ППГ) в течение многих лет ошибочно остается в группе «подозрение на глаукому» [5]. F. Daga и соавт. [6] считают, что выявление ППГ является значимым фактором в предупреждении развития ПОУГ, что обуславливает повышенный интерес исследователей к изучению предикторов ППГ [4, 7,8].

Термином ППГ обозначают глаукому, при которой имеются структурные нарушения ДЗН или изменения ПЗ, выявляемые с помощью коротковолновой сине-желтой автоматической периметрии (SWAP, Short Wavelength Automated Perimetry) или периметрии с удвоенной частотой (FDT, frequency doubling technology perimetry), в то время как показатели обычных методов периметрии (HFA, Octopus) остаются нормальными [9]. При этом могут наблюдаться изолированные нарушения на FDT без изменения толщины слоя нервных волокон сетчатки (СНВС), изменение СНВС без поражения ГКС или определяемые на ОКТ изменения СНВС и ГКС без нарушения в ПЗ [10]. Известно также, что структурные морфометрические изменения ДЗН нередко обнаруживаются до выявления функциональных глаукомных изменений с помощью периметрического теста с ахроматическим стимулом [11].

ЦЕЛЬЮ настоящего обзора явилось обобщение современных данных об основных параметрах диагностики ППГ.

J. Liebmann [12], J. Moreno-Monta и соавт. [13] подчеркивают важность перехода к новой парадигме, которая оставляет периметрию только для пациентов, нуждающихся в хирургическом лечении, а ОКТ - для всех обследуемых с подозрением на глаукому, с офтальмогипертензией и с уже установленным диагнозом глаукомы. К примеру, V. Begum и соавт. [14] с помощью ОКТ высокого разрешения (Cirrus HDOCT, Zeiss) не обнаружили разницы в толщине комплекса ГКС у пациентов с ППГ и лиц группы сравнения, тогда как параметры ДЗН и толщина перипапиллярного СНВС во всех секторах достоверно отличались $(\mathrm{p}<0,001)$.

Структурные изменения при ППГ происходят в ДЗН, в слое ГКС и СНВС. К характерным структурным изменениям ДЗН при ППГ относят: патологическое отклонение от нормы пропорций нейроретинального пояска (НРП, ОКТ-параметр rim volume), глаукомную экскавацию ДЗН (Э/ДЗН), перипапиллярную атрофию СНВС, клиновидные дефекты в СНВС, примыкающие к краю ДЗН, геморрагии по краю ДЗН. Н.И. Курышева и соавт. [4] к параметрам, которые необходимо исследовать при диспансерном наблюдении за больными глаукомой, относят: среднюю толщину СНВС и перипапиллярной хориоидеи, периметрический индекс PSD (pattern standart deviation), корнеальный гистерезис и диастолическую скорость кровотока в медиальных задних коротких цилиарных артериях.

В работе, проведенной Ј. Moreno-Monta и соавт. [13], продемонстрировано, что у пациентов с ППГ наблюдаются единичные $(16,6 \%)$ патологические изменения комплекса ГКС в макуле и толщине перипапиллярного СНВС. При этом диагноз ППГ был установлен на основании характерных изменений ДЗН (отклонение от нормы пропорций НРП, глаукомная экскавация ДЗН, перипапиллярная атрофия и геморрагии по краю ДЗН) и СНВС (клиновидные дефекты, примыкающие к краю ДЗН). Морфометрические обследования подтверждали указанные структурные изменения. При этом результаты САП соответствовали нормальным.

A. Kara-José и соавт. оценивали диагностическую точность шкалы вероятности повреждения ДЗН (DDLS) у больных ПОУГ. DDLS основана на измерении радиальной ширины НРП в наиболее тонкой ее части. DDLS показала сильную корреляцию с вертикальным $(\mathrm{r}=0,79)$ и горизонтальным $(\mathrm{r}=0,74)$ отношением Э/ДЗН. Клиническая оценка ДЗН с использованием системы DDLS и отношения Э/ДЗН продемонстрировала высокую точность в различении глаукомных и здоровых глаз [15].

Другими авторами показана значимость диаметра ДЗН. По данным Гейдельберской ретинотомографии (HRT, Heidelberg retinotomography) и ОКТ статистически достоверное различие всех параметров диска и перипапиллярной сетчатки в группе лиц с ДЗН средней величины может обеспечить выявление ПОУГ на ранних стадиях [8]. В группе пациентов с большими ДЗН только параметры перипапиллярной сетчатки показали статистически достоверное отличие от нормальных глаз по данным обоих методов исследования.

A. Miljkovic и соавт. [16] исследовали толщину СНВС у больных с ПОУГ и ППГ. Самые высокие показатели 
СНВС выявлены в верхнем квадранте в контрольной группе $(124,37 \pm 17,88 \mu \mathrm{m})$, а самые низкие - в височном квадранте в группе с развитой стадией ПОУГ $(46,50 \pm 10,85 \mu \mathrm{m})$, что и следовало ожидать. Средняя толщина СНВС была статистически значимо ниже у пациентов с ППГ, чем у здоровых лиц $(83,65 \pm 9,24$ и 105,57 $\pm 11,34 \mu$ т соответственно). Выявлена прямая корреляция между стадией ПОУГ и толщиной СНВС.

Исследование, проведенное Т. Aydogan К. и соавт. [17] с использованием метода спектральной OKT (SD-OCT, Spectral domain OCT), показало, что наиболее значимыми параметрами для ППГ являлись толщина СНВС и объем НРП, а ценность показателей толщины СНВС и комплекса ГКС увеличивается при прогрессировании заболевания.

Отмечены преимущества исследований параметров макулы для диагностики ППГ [18-25]. Обнаружено, что толщина комплекса ГКС имела большее значение для мониторинга заболевания, в то время как для ранней диагностики наиболее ценным оказалось определение толщины CHBC [19]. К подобным выводам пришли также S. Kaushik и соавт. [20].

Вместе с тем К. Кіт и соавт. [21] показали, что параметры комплекса ГКС у пациентов с разными стадиями ПОУГ имеют большее значение при прогрессировании заболевания, чем показатель СНВС.

По мнению Y. Kita и соавт. [24], G. Cennamo и соавт. [25], показатель комплекса ГКС в макулярной зоне (мГКС) является ранним и точным критерием структурного повреждения и прогрессирования глаукомы. При сравнении толщины мГКС и перипапиллярного СНВС авторы пришли к выводу, что для раннего выявления глаукомы последний показатель является менее ценным, так как более 30 \% ГКС расположены в области макулы [24, 25].

M. Kim и соавт. [26] продемонстрировали, что диагностическая ценность толщины слоя ГКС с внутренним плексиформным слоем - GCIPL (Ganglion cell and inner plexiform layer) у пациентов с ППГ сопоставима с перипапиллярной толщиной СНВС, причем на чувствительность параметра GCIPL существенное влияние оказывал внутренний угол направленности дефектов СНВС. Так, если височная граница дефекта СНВС находится далеко от фовеальной зоны, чувствительность макулярной карты GCIPL будет низкой. Если височная граница дефекта СНВС близка к фовеа, параметры макулярного GCIPL более чувствительны, чем параметры CHBC [26]. M. Sung и соавт. [27] подтвердили высокую диагностическую достоверность алгоритма карты отклонения толщины макулярного слоя GCIPL для дифференцирования ППГ или начальной ПОУГ и здоровых глаз.

X. Zhang и соавт. [28] отмечают, что информативность оценки СНВС снижается при прогрессировании ПОУГ, а оценка ГКС остается чувствительным детектором продвижения глаукомы от ранних до поздних стадий. Сравнение эффективности методов ОКТ и САП в выявлении прогрессирования ПОУГ показало, что по ОКТ прогрессирование глаукомного процесса было верифицировано значительно чаще $(\mathrm{p}<0,001)$, чем выявление прогрессии по данным периметрии. Скорость истончения СНВС резко замедлилась при прогрессировании ПОУГ, но частота истончения ГКС оставалась относительно стабильной и позволяла хорошо выявлять прогрессирование даже на поздней стадии заболевания [28].

У пациентов с ППГ S. Dubey и соавт. [29] обнаружили выраженное истончение слоя ГКС, а также связь между потерей ГКС и потерей СНВС при ППГ. Эти результаты свидетельствуют о возможности выявления ранних глаукоматозных повреждений при сопоставлении протокола СНВС с протоколом комплекса ГКС на RTVue (Optovue, США).
Б. Ангелов и К. Петрова [30] также обнаружили высокую чувствительность и специфичность (выше 90 \%) параметров карты ГКС, что свидетельствует об их особой точности при диагностике ПОУГ. Максимальную диагностическую значимость в группе ППГ имел индекс глобальной потери объема (GLV) (0,981), а самую низкую - толщина комплекса ГКС в верхней части (Sup. GCC). Диагностическая точность анализируемых показателей в случае ППГ выше, чем при офтальмогипертензии (ОГ) [31].

C помощью SD-OKT макулярной области Е. Kim и соавт. [32] оценивали толщину СНВС, комплекс ГКС внутреннего плексиформного слоя (IPL, inner plexiform layer) и слой ГKC c GCIPL, сравнивали структурно-функциональные особенности этих четырех параметров у больных ПОУГ с помощью САП (поле 24-2). Выявлено, что толщина IPL в значительной степени связана со стадией глаукомы. Анализ внутреннего слоя сетчатки, включая IPL в макулярной области, представляет ценность для ранней диагностики ПОУГ [32]. К подобным выводам пришли также H. Moon и соавт. [33], которые около 4 лет наблюдали за пациентами с ППГ и ПОУГ. Исследователи полагают, что последовательное изучение GCIPL играет важную роль в ранней диагностике, а также оценке прогрессирования ПОУГ.

По мнению T. Rolle и соавт. [34], анализ ГКС, проведенный с помощью RTVue-100, может использоваться в качестве достоверного метода ранней диагностики, определяющего нейронные потери при глаукоме.

Спектральная ОКТ с модулем улучшенной глубины изображения (EDI-SDOCT) позволяет проводить анализ решетчатой пластинки склеры (РПС) и оценивать ее в трех измерениях. С помощью данного метода выполнено исследование 112 глаз пациентов с ППГ, имеющих нормальную толщину перипапиллярного СНВС. При этом изучалась ширина неврального ободка по горизонтали - BMO-HRW (Bruch's membrane opening - horizontal rim width), минимальная ширина неврального ободка по горизонтали - ВMOMRW (Bruch's membrane opening - minimum rim width), определялась форма склерального канала, исследовалась макулярная область сетчатки, изучалось количество клеток пигментного эпителия [35, 36]. Авторы данных работ относят характерную форму склерального канала (U-образную), уменьшение количества клеток пигментного эпителия и показатель BMO-MRW к важным параметрам, которые можно успешно использовать в диагностике ППГ. Исследование схожих параметров встречается и в работе J. Gmeiner и соавт. [37]. Особо отмечена важность показателей толщины СНВС и минимального расстояния между мембраной Бруха и внутренней пограничной мембраной в диагностике ППГ. Так, у пациентов с ППГ выявлено истончение СНВС, особенно в нижненосовом сегменте, и уменьшение показателя ВМОMRW, преимущественно в верхних и нижних секторах [37].

С помощью широкоформатной OKT (SS-OCT) H. Akil и соавт. [38] оценивали толщину сосудистой оболочки и определяли связь данного параметра с толщиной СНВС и ГКС у пациентов с ППГ и ПОУГ, а также в здоровых глазах. Установлено, что толщина хориоидеи составляет у пациентов с глаукомой, ППГ и у здоровых лиц $111,7 \pm 41,7,127,7 \pm 40,1$ и $120,8 \pm 35,4$ мкм соответственно. Авторы исследования считают, что SS-OCT может применяться в качестве дополнительного метода диагностики глаукомы [38].

K. Omodaka и соавт. [39] изучали связь толщины РПС с возрастом, уровнем ВГД, величиной частоты сердечных сокращений, уровнем артериального давления, длиной переднезадней оси глаза, параметрами кровотока в области ДЗН у пациентов с ППГ и ПОУГ. Достоверных различий по 
изучаемым параметрам не выявлено. Установлено только значимое уменьшение толщины РПС по мере развития глаукомы. Показатель толщины РПС коррелировал с MD $(0,47, \mathrm{p}<0,001)$, со средним СНВС $(0,57, \mathrm{p}<0,001)$, с отношением Э/ДЗН $(-0,52, \mathrm{p}<0,001)$. Эти параметры авторы считают ценными для оценки тяжести ПОУГ. Кроме этого, с помощью спекл-флоуметрии у пациентов с ППГ выявлено ухудшение кровотока в области ДЗН [39].

W. Lee и соавт. [40] в ходе наблюдений 43 пациентов (43 глаза) с ППГ, которым каждые 6 мес в течение 2 лет проводилась SAP и SS-OCT, пришли к выводу, что с помощью карт вероятности SS-OCT можно выявить или предположить возможное изменение в ПЗ (САП), а сравнение данных, полученных при SS-OCТ и САП, способно помочь в диагностике и мониторинге ППГ. Проводили оценку уязвимых точек ПЗ с помощью карт вероятности SS-OCT, а также динамику зон со значительным снижением светочувствительности, наблюдаемых в соответствующих поврежденных областях карт вероятности. В 16 (37,2\%) из 43 глаз с ППГ в течение периода наблюдения обнаружились новые изменения в ПЗ в тех областях, где были прогнозированы изменения [40]. Таким образом, структурные изменения, полученные с помощью SS-OCT, могут выявлять и прогнозировать изменения ПЗ при ППГ.

Периметрия при препериметрической глаукоме. Известно, что первые отклонения от нормы при периметрической глаукоме можно выявить при проведении SWAP, FDT-периметрии или ахроматической периметрии. Однако A. Sawada и соавт. [41] доказали чувствительность SAP, проведя ретроспективный анализ данных пациентов с установленным диагнозом ППГ и нормальным ВГД в течение 5 лет. Диагноз выставлялся при соответствующих ПОУГ дефектах в П3, которые последовательно повторялись в 3 и более исследованиях. В 54,6 \% случаев в ходе наблюдения в ПЗ были выявлены характерные для глаукомы изменения. Кроме этого, у пациентов определялись геморрагии на ДЗН $(\mathrm{p}=0,022)$ и повышенное ВГД $(\mathrm{p}=0,039)$ до появления дефектов в ПЗ. Показано, что именно повышение ВГД, а не его колебания являются основной причиной появления нарушений в ПЗ.

R. Asaoka и соавт. [42] провели многоцентровое ретроспективное исследование 790 пациентов с ПОУГ или с подозрением на глаукому. Из этих пациентов отобрали 87 глаз с ППГ и сравнили с данными 108 здоровых пациентов. Значения среднего отклонения (MD) и PSD у здоровых людей были значительно больше, чем у пациентов с ППГ. Среднее время перехода к первым глаукоматозным показателям ПЗ пациентов с ППГ составил 271,1 дня.

M. Benova и соавт. [43] для исследования дефектов центрального П3 (от 4 до 28 градусов) при ППГ применяли периметрию с использованием микроточек - Rarebit (RBP). Авторы считают этот метод чувствительным (65,2-91,3\% в сравнении со здоровыми глазами) и специфичным (66,7-95,8 \%) в плане определения дефектов ПЗ при ППГ в сравнении с САП, кроме того, данный тест выполняется легко и быстро.

В то же время К. Jung и соавт. [44, 45] установили, что ранние изменения в макуле при глаукоме у больных с ППГ и периметрической глаукомой лучше определяются с помощью FDT, чем САП ( $<<0,01)$. FDT-периметрия с удвоением частоты основана на оптической иллюзии, заключающейся в том, что черно-белая решетка создает иллюзию наличия вдвое большего числа полос. Все пациенты, имеющие нарушения в П3, выявленные с помощью обоих методов, имели меньшую толщину слоя ГКС, чем пациенты без аномалий
П3 (p < 0,05). Авторы рекомендуют FDT-10-2-периметрию для ранней диагностики ПОУГ [44, 45].

M. Eura и соавт. [46] проводили оценку связи периметрических тестов с показателями SD-OCT - комплекса GCC и IPL у пациентов с ППГ, больных с начальной и развитой стадиями ПОУГ. Проводили 3 САП - 10-2 НFА c SITA-HFA SITA (III), HFA FULL (III) и HFA FULL (I) и 3 специальных исследования П3 (10-2 SWAP, 10-2 flicker, 10-2 Humphrey Matrix). SWAP - коротковолновая синежелтая периметрия, позволяет выделить и изолированно оценить функцию так называемых синих колбочек, а также соответствующих им ГКС и вышележащих отделов кониоцеллюлярного зрительного пути. Все 6 тестов показали самую сильную корреляцию с толщиной GCL + IPL в области 5-7 градусов. Таким образом, при исследовании макулярной области у больных глаукомой авторы рекомендуют САП с размером стимула I, а также 10-2 SWAP, 10-2 flicker, 10-2 Humphrey Matrix [46].

Н. Kim и соавт. [47] при 6-летнем наблюдении пациентов с впервые установленной ППГ показали, что вероятность появления дефектов ПЗ у пациентов с геморрагиями на ДЗН в 2 раза выше, чем у пациентов без геморрагий (45,4 мес против 73,3 мес), а временной интервал от момента выявления ППГ до появления дефектов в ПЗ у больных, имеющих кровоизлияния на ДЗН, значительно короче. P. Sriram и соавт. [11] изучали чувствительность комбинации функциональных и структурных тестов для выявления ППГ. Все участники прошли полное офтальмологическое обследование, включающее периметрию, SWAP, FDT, а также OKT, HRT-3 и цветовую стереоскопическую фотографию ДЗН. Тест с ахроматическим стимулом выявил, как HRT-3, приблизительно 50,6 \% глаз с ППГ и был значительно информативнее, чем другие периметрические методы. Комбинация ахроматического паттерна и НRT-3 имела исключительно высокую чувствительность (76,5 \%) для ППГ.

Исследование кровотока при ППГ. По данным J. Hwang и соавт. [48], сниженные показатели ретинального кровотока и морфометрических параметров являются независимыми предикторами появления дефектов ПЗ. Причем показатели глазного кровотока в 2 раза более точно позволяли предвидеть функциональные расстройства, чем изменения морфометрических показателей (толщина СНВС и параметры GCC).

Y. Shiga и соавт. [49] оценивали кровоток в области ДЗН в здоровых глазах, у пациентов с ППГ и с глаукомой псевдонормального давления, используя лазерную спеклфлоуметрию. Выявлено достоверное снижение кровотока в области ДЗН у больных с ППГ $(\mathrm{p}=0,001)$. Авторы считают, что данный метод может применяться для мониторинга на ранних стадиях глаукомы. R. Kumar и соавт. [50], используя метод OKT-ангиографии SD-OKT, выявили значительное нарушение кровотока $(\mathrm{p}<0,001)$ в глазах с ППГ по сравнению с контрольной группой в верхнетемпоральном, верхненосовом и нижнетемпоральном секторах.

G. Holló [51] представил результаты наблюдения за 68-летней больной с ПОУГ на правом глазу и ППГ на левом глазу, которая на протяжении 20 лет получала гипотензивную терапию. В ходе динамического наблюдения за пациенткой было отмечено повышение ВГД, появление характерных для ПОУГ изменений в П3, а также прогрессирующее снижение плотности перипапиллярных сосудов. Одновременное истончение СНВС, ГКС и уменьшение плотности сосудов вокруг ДЗН позволяют предположить, что изучение плотности перипапиллярного сосудистого русла может помочь в ранней диагностике глаукомы [51]. 
W. Schrems и соавт. [52] определяли прогностическую ценность измерений толщины СНВС, полученных с помощью ОКТ, морфометрических параметров конфокальной сканирующей лазерной офтальмоскопии (CSLO) и периметрического метода удвоения частоты для прогнозирования изменений в ПЗ у здоровых людей, пациентов с ОГ и ППГ. Установлено, что и измерение толщины СНВС с помощью ОКТ, и оценка вероятности глаукомы с помощью CSLO в значительной степени прогнозируют будущие изменения ПЗ [52].

N. Aizawa и соавт. [53] исследовали 122 пациента с впервые выявленной ППГ: измеряли толщину перипапиллярного СНВС с помощью ОКТ и оценивали кровоток в области ДЗН с помощью лазерной спекл-флоуметрии. Самый высокий процент дефектов $(43,4$ \%) выявлен в нижневисочном квадранте СНВС при ОКТ. На фоне тафлупроста, кроме достоверного снижения ВГД, зафиксировано достоверное повышение окулярной перфузии с 43,0 \pm 10,2 до $45,3 \pm 9,3$ мм рт. ст. в течение 4 мес $(\mathrm{p}=0,001)$. По мнению G. Cennamo и соавт. [25], снижение перипапиллярной перфузии и структурные изменения являются первыми признаками начинающейся глаукомы, а отсутствие корреляции между данными периметрии и ОКТ-ангиографии у больных с ППГ свидетельствует о том, что первичным звеном является снижение перипапиллярной перфузии, которое затем приводит к функциональным последствиям.

Электроретинография (ЭРГ) и лечение препериметрической глаукомы. V. Porciatti и L. Ventura [54] представили концептуальную модель структурно-функциональных отношений для одиночной ГКС на разных стадиях ее прогрессивной дисфункции и смерти и для большой популяции ГКС с различными уровнями клеточной дисфункции. Авторы отмечают, что активность ГКС, по данным паттерн-ЭРГ (ПЭРГ), может изменяться задолго до снижения толщины СНВС. Этот период в течении глаукомной оптической нейропатии получил название «критического периода дисфункции», предшествующего смерти аксонов, а затем и самой ГКС. Другое его название - «пластический» период, когда ухудшение ГКС и их аксонов, по данным ПЭРГ, можно обратить вспять или, наоборот, индуцировать. Идентификация этой пластичной стадии, как полагают авторы, является основанием для назначения лечения, а сам критический период дисфункции аксонов - мишенью для терапии, которая могла бы изменить естественное течение ГОН. Таким образом, при глаукоме графики изменений структуры и функции сдвинуты по времени. ГКС способны медленно изменять свою функцию в течение долгого времени, и лечение, примененное во время «пластического» периода, может существенно изменить течение заболевания [54].

J. Karaskiewicz и соавт. [55] оценивали функции ГКС после снижения ВГД по ЭРГ у пациентов с ППГ и начальной стадией ПОУГ. В качестве гипотензивного препарата использовался ганфорт. Выявлено, что после месяца лечения во всех глазах в среднем на 31 \% снизилось ВГД, улучшилось перфузионное давление - на $11 \%$, амплитуда ЭРГ-показателей (волн Р50 и N95) увеличилась в 75 и $79 \%$ случаев. Зависимости между изменениями параметров ЭРГ и стадией глаукомы не было установлено. Авторы статьи считают, что эффективная гипотензивная терапия улучшает функции ГКС у пациентов с ППГ и начальной стадией глаукомы. По данным А. Kreuz и соавт. [56], имеется значимая связь между данными ЭРГ и большинством параметров ОКТ и компьютерной периметрии (КП), поэтому все эти технологии могут быть полезны в ранней диагностике глаукомы. С этой целью были предложены 3 вида калькуляторов: количественные (числовые данные), качественные (данные в зеленом, желтом и красном цветах) и комбинированные. Каждый из них оценивает определенные параметры (ОКТ и КП) и на основании их анализа делает вывод о наличии или отсутствии глаукомы. Значения калькуляторов выше в группе ППГ, чем в группе глазной гипертензии. Все предложенные калькуляторы облегчают принятие решения о наличии или отсутствии глаукомы у конкретного пациента [13].

\section{ЗАКЛЮЧЕНИЕ}

Несмотря на возможности современной диагностической аппаратуры, вопрос выявления глаукомы на ранней стадии, в частности до появления характерных изменений в ПЗ, остается достаточно актуальным. Необходимо увеличить частоту применения метода ЭРГ при ППГ и расширить применение ОКТ-ангиографии, так как эти способы позволяют выявить наиболее ранние признаки заболевания. ОКТ может позволить установить диагноз ПОУГ приблизительно на 5-12 лет раньше, чем появятся первые дефекты в П3, однако диагностические возможности верификации ранней стадии глаукомы снижены по сравнению со способностью обнаружения продвинутых стадий заболевания [3, 4]. Калькуляторы, учитывающие изменения ОКТ и даже обычной периметрии (Humphrey или Octopus), позволяют нивелировать этот недостаток [13]. Для диагностики ППГ большое значение имеет кратность наблюдений, которую необходимо по возможности увеличивать. Важную роль в выявлении различных факторов риска, например повышения ВГД и кровоизлияний на ДЗН, играет частота структурных и функциональных исследований. Выявление подобных отклонений может повлиять на сроки начала лечения таких больных [4]. Необходимо отметить, что до настоящего времени нет четких рекомендаций по лечению пациентов с ППГ, этот вопрос требует дальнейшего изучения.

\section{Jumepamypa/References}

1. Чеченина Н.Г., Шапошникова И.В., Фролова Е.А., Лемберг О.В. Основные источники выявления глаукомы на амбулаторном приеме. Русский медицинский журнал. Клиническая офтальмология. 2008; 4: 119-20. [Chechenina N.G., Shaposhnikova I.V., Frolova E.A., Lemberg O.V. Main sources of glaucoma detection at out-patient admission. RMJ. Clinical Ophthalmology. 2008; 4: 119-20 (in Russian)].

2. Фабрикантов О.Л., Шутова С.В., Сухорукова А.В. Сравнительная характеристика методов стандартной компьютерной и контурной периметрии в диагностике начальной глаукомы. Офтальмохирургия. 2015; 4: 24-9. [Fabrikantov O.L., Shutova S.V., Sukhorukova A.V. Comparative characteristics of the standard automated perimetry and contour perimetry methods in diagnosis the initial stage of glaucoma. Ophthalmokhirurgija. 2015; (4): 24-9 (in Russian)].

3. Азнабаев Б.М., Мухамадеев Т.Р., Дибаев Т.И. Оптическая когерентная томография + ангиография глаза. Москва: Август Борг. 2015. [Aznabaev B.M., Mukhamadeev T.R., Dibaev T.I. Optical coherence tomography + angiography of the eye. Moscow: August Borg; 2015 (in Russian)].

4. Курышева Н.И., Паршунина О.А., Арджевнишвили Т.Д. и др. Новые технологии в диагностике первичной открытоугольной глаукомы. Национальный журнал глаукома. 2015; 14 (2): 22-31. [Kurysheva N.I., Parshunina O.A., Ardzhevnishvili T.D., et al. New technologies in primary open-angle glaucoma diagnostics. Glaucoma. 2015; 14 (2): 22-31(in Russian)].

5. Harasymowycz P., Birt C., Gooi P., et al. Medical management of glaucoma in the 21st century from a Canadian perspective. J. Ophthalmol. 2016; 2016: 6509809. doi: $10.1155 / 2016 / 6509809$

6. Daga F.B., Gracitelli C.P.B., Diniz-Filho A., et al. Is vision-related quality of life impaired in patients with preperimetric glaucoma? Br. J. Ophthalmol. 2019; 103 (7): 955-9. doi: 10.1136/bjophthalmol-2018-312357

7. Takagi S.T., Kita Y., Yagi F., Tomita G. Macular retinal ganglion cell complex damage in the apparently normal visual field of glaucomatous eyes with hemifield defects. Glaucoma. Jun-Jul 2012; 21 (5): 318-25. doi: 10.1097/ IJG.0b013e 31820d7e 9d

8. Львов В.А., Мачехин В.А., Фабрикантов О.Л. Сравнительный анализ морфометрических параметров диска зрительного нерва при глаукоме в группах глаз со средними по величине и большими дисками. Саратовский на- 
учно-медицинский журнал. 2019; 15 (2): 510-4. [L'vov V.A., Machekhin V.A., Fabrikantov O.L. Comparative analysis of morphometric parameters of the optic disk in glaucomatous eyes with discs of average and large size. Saratovskiy nauchno-medicinsikij zhurnal. 2019; 15 (2): 510-4 (in Russian)].

9. Чоплин Н.Т., Ланди Д.С. Глаукома. Иллюстрированное руководство. Москва: Логосфера; 2011. [Choplin N.T., Landy D.S. Atlas of Glaucoma. Moscow: Logosphera; 2011 (in Russian)].

10. Nordmann J. Ph. OCT \& Optic nerve. Paris: Laboratoire Théa and Carl Zeiss Meditec. France SAS: 2014.

11. Sriram P., Klistorner A., Graham S., Grigg J., Arvind H. Optimizing the detection of preperimetric glaucoma by combining structural and functional tests. Invest. Ophthalmol. Vis. Sci. 2015; 56: 7794-800. doi:10.1167/iovs.15-16721

12. Liebmann J. M. Ophthalmology and glaucoma practice in the COVID-19 Era. Journal of Glaucoma. Published Ahead-of-Print. 2020; April 14. doi: 10.1097/ IJG.0000000000001519

13. Moreno-Monta J., Garcia-Nieva A., Osio I.A., et al. Evaluation of RETICs glaucoma diagnostic calculators in preperimetric glaucoma. Trans. Vis. Sci. Tech. 2018; 7 (6): 13. doi:10.1167/tvst.7.6.13

14. Begum V.U., Addepali U.K., Senthil S., et al. Optic nerve head parameters of high-definition optical coherence tomography and Heidelberg retina tomogram in perimetric and preperimetric glaucoma. Indian J. Ophthalmol. 2016; 64 (4): 277-84. doi:10.4103\%2F0301-4738.182938

15. Kara-José A.C., Melo L.A.S. Jr., Esporcatte B.L.B., et al. The disc damage likelihood scale: Diagnostic accuracy and correlations with cup-to-disc ratio, structural tests and standard automated perimetry. PLoS One. 2017; 12 (7): e0181428. doi:10.1371/journal.pone.0181428

16. Miljkovic A., Babic N., Davidovic S., et al. Peripapillary retinal nerve fibre thickness in patients with primary open-angle glaucoma. BMC ophthalmology. 2019. doi:10.21203/rs.2.16429/v1

17. Aydogan T.K., Akcay B.I.S., Kardes E., Ergin A.H. Evaluation of spectral domain optical coherence tomography parameters in ocular hypertension, preperimetric, and early glaucoma. Indian J. Ophthalmol. 2017: 65 (11): 1143-50. doi: 10.4103/ijo.IJO_157_17

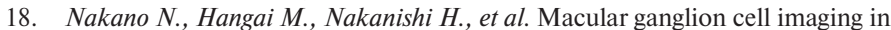
preperimetric glaucoma with speckle noise-reduced spectral domain optical coherence tomography. Ophthalmol. 2011; 118 (12): 2414-26. doi: 10.1016/j. ophtha.2011.06.015

19. Курышева Н.И. Оптическая когерентная томография в диагностике глаукомы. Москва: Гринлайт; 2015. [Kurysheva N.I. Optical coherence tomography in the diagnosis of glaucoma. Moscow: Grinlayt; 2015 (In Russian)].

20. Kaushik S., Kataria P., Jain V., et al. Evaluation of macular ganglion cell analysis compared to retinal nerve fiber layer thickness for preperimetric glaucoma diagnosis. Indian J. Ophthalmol. 2018; 66 (4): 511-6. doi: 10.4103/ ijo.IJO_1039_17

21. Kim K.E., Park K.H., Jeoung J.W., et al. Severity-dependent association between ganglion cell inner plexiform layer thickness and macular mean sensitivity in open-angle glaucoma. Acta Ophthalmol. 2014; 92: 650-6. doi: 10.1111/ aos. 12438

22. Oddone F., Lucenteforte E., Michelessi M., et al. Macular versus retinal nerve fiber layer parameters for diagnosing manifest glaucoma: a systematic review of diagnostic accuracy studies. Ophthalmology. 2016; 123:939-49. doi: 10.1016/j. ophtha.2015.12.041

23. Naghizadeh F., Garas A., Vargha P., Holló G. Detection of early glaucomatous progression with different parameters of the RTVue optical coherence tomograph. J. Glaucoma. 2014; 23: 195-8. doi: 10.1097/IJG.0b013e31826a9707

24. Kita Y., Soutome N., Horie D., Kita R., Hollo G. Circum papillary ganglion cell complex thickness to diagnose glaucoma: a pilot study. Indian J. Ophthalmol. 2017; 65 (1): 41-7. doi: 10.4103/ijo.IJO 43716

25. Cennamo G., Montorio D., Velotti N., et al. Optical coherence tomography angiography in preperimetric open angle glaucoma. Graefes Arch. Clin. Exp. Ophthalmol. 2017; 255 (9): 1793-7. doi: 10.1007/s00417-017-3709-7

26. Kim M.J., Jeoung J.W., Park K.H., Choi Y.J., Kim D.M. Topographic profiles of retinal nerve fiber layer defects affect the diagnostic performance of macular scans in preperimetric glaucoma. Invest. Ophthalmol. Vis. Sci. 2014; 55: 2079-87. doi:10.1167/iovs.13-13506

27. Sung M.-S., Yoon, J.-H., Park, S. $-W$. Diagnostic validity of macular ganglion cell-inner plexiform layer thickness deviation map algorithm using Cirrus HD-OCT in preperimetric and early glaucoma. J. Glaucoma. 2014; 23 (8): e144-e151. doi:10.1097/ijg.0000000000000028

28. Zhang X., Dastiridou A., Francis B.A., et al. Comparison of glaucoma progression detection by Optical Coherence Tomography and visual field. Am. J. Ophthalmol. 2017; 184: 63-74. doi:10.1016/j.ajo.2017.09.020

29. Dubey S., Prasanth B., Chauhan L., Mukherjee S. Detection of ganglion cell loss in preperimetric glaucoma by Fourier-Domain Optical Coherence Tomography. Int. J. Clin. Exp. Ophthalmol. 2017; 1: 42-8. doi:10.29328/ journal.hceo. 1001006

30. Ангелов Б., Петрова К. Диагностическая точность некоторых показателей карты ганглиозно-клеточного комплекса, измеренных с помошью SDОСТ при первичной открытоугольной глаукоме. Офтальмология. 2014 11 (3): 28-32. [Angelov B., Petrova K. Diagnostic accuracy of the parameters from ganglion cell complex map, evaluated with SD-OCT in primary openangle glaucoma. Ophthalmology in Russia. 2014; 11 (3): 28-32 (in Russian). doi:10.18008/1816-5095-2014-3-28-32]

31. Ангелов Б., Петрова Н. Оптическая когерентная томография и ее роль в диагностике глазной гипертензии, препериметрической и периметрической глаукомы. Офтальмология.2015; 12 (1): 46-56. [Angelov B., Petrova $K$. Optical coherence tomography and its role in the diagnosis of ocular hypertension, preperimetric and perimetric glaucoma. Ophthalmology in Russia. 2015; 12 (1): 46-56 (in Russian). doi:10.18008/1816-5095-2015-1-46-56]

32. Kim E.K., Park H.L., Park C.K. Segmented inner plexiform layer thickness as a potential biomarker to evaluate open-angle glaucoma: Dendritic degeneration of retinal ganglion cell. PLoS One. 2017; 12 (8): e0182404. doi: 10.1371/journal. pone. 0182404

33. Moon H., Lee J.Y., Sung K.R., Lee J.E. Macular ganglion cell layer assessment to detect glaucomatous central visual field progression. Korean J. Ophthalmol. 2016; 30 (6): 451-8. doi:10.3341/kjo.2016.30.6.451

34. Rolle T., Dallorto L., Bonetti B. Retinal and macular ganglion cell count estimated with optical coherence tomography RTVue-100 as a candidate biomarker for glaucoma. Invest. Ophthalmol. Vis. Sci. 2016; 57 (13): 5772-9. doi:10.1167/ iovs. $15-18882$

35. Hua R., Gangwani R., Guo L., et al. Detection of preperimetric glaucoma using Bruch membrane opening, neural canal and posterior pole asymmetry analysis of optical coherence tomography. Scientific Reports. 2016; 6: 21743. doi: 10.1038/ srep 21743

36. Курышева Н.И., Паршутина О.А. Оптическая когерентная томография в диагностике глаукомной оптиконейропатии. Часть 1. Национальный журнал Глаукома. 2016; 15 (1): 86-96. [Kurysheva N.I., Parshutina O.A. Optical coherence tomography in glaucoma optic neuropathy diagnostics. Part 1. Glaucoma. 2016; 15 (1): 86-96 (in Russian)].

37. Gmeiner J.M., Schrems C.Y., Mardin C.Y., et al. Comparison of Bruchs membrane opening minimum rim width and peripapillary retinal nerve fiber layer thickness in early glaucoma assessment. Invest. Ophthalmol. Vis. Sci. 2016; 57: 575-84. doi: 10.1167/iovs.15-18906

38. Akil H., Al-Sheikh M., Falavarjani K.G., et al. Choroidal thickness and structura glaucoma parameters in glaucomatous, preperimetric glaucomatous, and healthy eyes using swept-source OCT. Eur. J. Ophthalmol. 2017; 27 (5): 548-54. doi: $10.5301 /$ ejo. 5000926

39. Omodaka K., Takahashi S., Matsumoto A., et al. Clinical factors associated with lamina cribrosa thickness in patients with glaucoma, as measured with swept source optical coherence tomography. PLoS One. 2016; 11(4): e0153707. doi:10.1371/journal.pone.0153707

40. Lee W.J., Kim Y.K., Jeoung J.W., Park K.H. Can probability maps of SweptSource Optical Coherence Tomography predict visual field changes in preperimetric glaucoma? Invest Ophthalmol Vis. Sci. 2017; 58 (14): 6257-64. doi: 10.1167 /iovs. 17-22697

41. Sawada A., Manabe Y., Yamamoto T., Nagata C. Long-term clinical course of normotensive preperimetric glaucoma. Br. J. Ophthalmol. 2017; 101 (12): 1649-53. doi: 10.1136/ bjophthalmol-2016-309401

42. Asaoka $R$., Iwase A., Hirasawa $K$, et al. Identifying «preperimetric» glaucoma in Standard Automated Perimetry Visual Fields. Invest. Ophthalmol. Vis. Sci. 2014; 55: 7814-20. doi:10.1167/ iovs.14-15120

43. Benova M., Shumnalieva V., Zdravkov Y., Tanev I. Application of Rare bit perimetry in preperimetric glaucoma. Bulg. Rev. Ophthalmol. 2017; 61: 27-32. doi:10.14748/bro.v0i1.5232

44. Jung K.I., Park H-Y.L., Park Y.R., Park C.K. Use fullness of 10-2 matrix frequency doubling technology perimetry for detecting central visual field defects in preperimetric glaucoma patients. Sci. Rep. 2017; 7: 14622. doi: 10.1038/ s41598-017-15329-1

45. Jung K.I., Park C.K. Detection of functional change in preperimetric and perimetric glaucoma using 10-2 Matrix Perimetry. Am. J. Ophthalmol. 2017; 182: 35-44. doi:10.1016/ j.ajo.2017.07.007

46. Eura M., Matsumoto C., Hashimoto $S$., et al. Test conditions in macular visual field testing in glaucoma. J. Glaucoma. 2017; 26 (12): 1101-6. doi: 10.1097/ IJG.0000000000000782

47. Kim H.J., Song Y.J., Kim Y.K., et al. Development of visual field defect after first-detected optic disc hemorrhage in preperimetric open-angle glaucoma. J. Ophthalmol. 2017; 61 (4): 307-13. doi:10.1007/s10384-017-0509-X

48. Hwang J., Konduru R., Zhang X., et al. Relationship among visual field, blood flow, and neural structure measurements in glaucoma. Invest. Ophthalmol. Vis. Sci. 2012; 53: 3020-6. doi: 10.1167/iovs.11-8552

49. Shiga Y., Kunikata H., Aizawa N., et al. Optic nerve head blood flow, as measured by laser specleflowgraphy, is significantly reduced in preperimetric glaucoma. Cur. Eye Res. 2016; 41 (11): 1447-53. doi:10.3109/02713683.2015.1127974

50. Kumar R.S., Anegondi N., Chandapura R.S., et al. Discriminant function of optical coherence tomography angiography to determine disease severity in glaucoma. 
Invest. Ophthalmol. Vis. Sci. 2016; 57 (14): 6079-88. doi:10.1167/iovs.16-19984

51. Holló $G$. Progressive decrease of peripapillary angioflow vessel density during structural and visual field progression in early primary open-angle glaucoma. J. Glaucoma. 2017; 26 (7): 661-4. doi:10.1097/IJG.0000000000000695

52. Schrems W.A., Schrems-Hoesl L.M., Mardin C.Y., et al. Can glaucomatous visual field progression be predicted by structural and functional measures? J. Glaucoma. 2017; 26 (4): 373-82. doi:10.1097/IJG.0000000000000628

53. Aizawa N., Kunikata H., Shiga Y., et al. Preperimetric Glaucoma Prospective Observational Study (PPGPS): design, baseline characteristics, and therapeutic effect of tafluprost in preperimetric glaucoma eye. PLoS ONE 12 (12): e0188692. doi: 10.1371/journal.pone. 0188692
54. Porciatti V., Ventura L.M. Retinal ganglion cell functional plasticity and optic neuropathy: a comprehensive model. J. Neuroophthalmol. 2012; 32 (4): 354-8. doi: 10.1097/WNO.0b013e3182745600

55. Karaskiewicz.J., Penkala K., Mularczyk M., Lubinski W. Evaluation of retinal ganglion cell function after intraocular pressure reduction measured by pattern electroretinogram in patients with primary open-angle glaucoma. Doc. Ophthalmol. 2017; 134 (2): 89-97. doi: 10.1007/s10633-017-9575-0

56. Kreuz, A.C., Moraes C.G., Hatanaka M., et al. Macular and multifocal PERG and FD-OCT in preperimetric and hemifield loss glaucoma. J. Glaucoma. 2018; 27 (2): 121-32. doi: 10.1097/IJG.0000000000000857

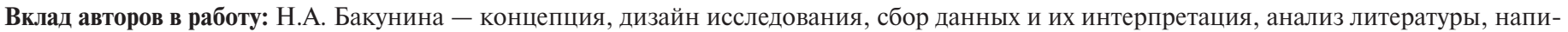

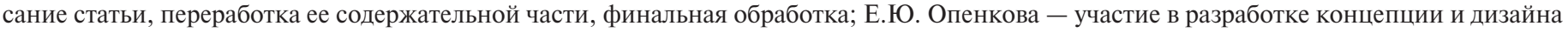

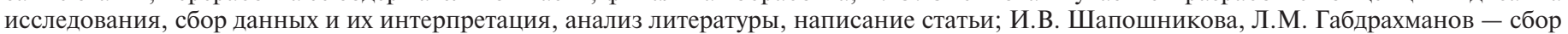

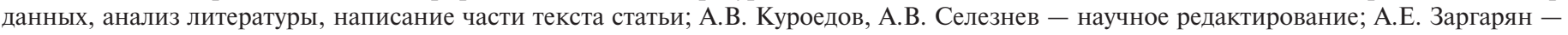
участие в сборе данных для части статьи.

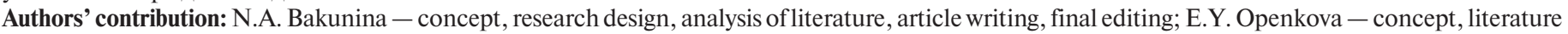

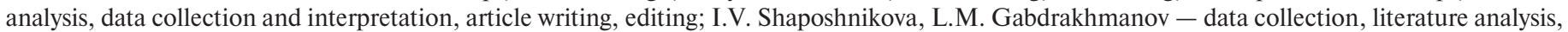

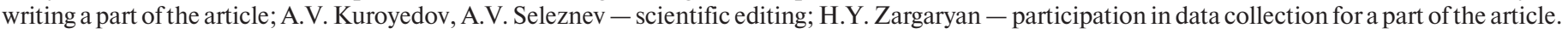

\section{ИНФОРМАЦИЯ ОБ АВТОРАХ / INFORMАТION ABOUT THE AUTHORS}

ГКБ № 1 им. Н.И. Пирогова, Ленинский проспект, д. 8, Москва, 119049, Россия

Наталья Александровна Бакунина - канд. мед. наук, врачофтальмолог

МАУЗ ОЗП ГКБ № 8, ул. Горького, д. 28, Челябинск, 454071, Россия

Елена Юрьевна Опенкова - канд. мед. наук, врач-офтальмолог ООО «ОЦ "Хорошее зрение", ул. Рукавишникова, д. 20, Кемерово, 650000, Россия

Ирина Вячеславовна Шапошникова - врач-офтальмолог

ГБУЗ СОКОБ им. Т.И. Ерошевского, ул. Ново-Садовая, д. 158, Самара, 443068, Россия

Ленар Маратович Габдрахманов - канд. мед. наук, врач-офтальмолог ${ }^{\prime}$ ФКУ «ЦВКГ им. П.В. Мандрыка», ул. Б. Оленья, д. 8а, Москва, 107014, Россия

${ }^{2}$ ФГАОУ ВО «РНИМУ им. Н.И. Пирогова» Минздрава России, ул. Островитянова, д. 1, Москва, 117997, Россия

Александр Владимирович Куроедов - д-р мед. наук, начальник отделения ${ }^{1}$, профессор кафедры ${ }^{2}$

ФГБОУ ВО «ИвГМА» Минздрава РФ, пр. Шереметевский, д. 8, Иваново, 153012, Россия

Алексей Владимирович Селезнев - канд. мед. наук, доцент кафедры Офтальмологическая клиника «Доктор Глазов», ул. Пролетарская, д. 7, Балашиха, 143980, Россия

Асмик Ерджаниковна Заргарян - канд. мед. наук, врач-офтальмолог

Для контактов: Наталья Александровна Бакунина, nata-oko@mail.ru
N.I. Pirogov City clinical hospital N 1, 8, Leninsky prospect, Moscow, 119049, Russia

Natalia A. Bakunina - Cand. of Med. Sci., ophthalmologist. https://orcid. org/0000-0002-1148-5184

Municipal Autonomous health institution "City Clinical Hospital N 8", 28, Gor'kogo St., Chelyabinsk, 454071, Russia

Elena Yu. Openkova - Cand. of Med. Sci., ophthalmologist. https://orcid. org/0000-0002-4776-5743

Good Vision Center, 20, Rukavishnikova St., Kemerovo, 650000, Russia

Irina V. Shaposhnikova - ophthalmologist. https://orcid.org/0000-00030927-6591

Samara T.I. Eroshevsky Regional Clinical Ophthalmological Hospital, 158, Novo-Sadovaya St., Samara, 443068, Russia

Lenar M. Gabdrakhmanov - Cand. of Med. Sci., ophthalmologist. https:// orcid.org/0000-0001-5847-2017

${ }^{1}$ Mandryka Central Clinical Hospital, 8A, Bolshaya, Olen ya St., 107014, Moscow, Russia

${ }^{2}$ N.I. Pirogov Russian National Research Medical University, 1, Ostrovityanova St., 117997 Moscow, Russia

Alexandr V. Kuroyedov - Dr. of Med. Sci., head of ophthalmology department ${ }^{1}$, professor $^{2}$. https://orcid.org/0000-0001-9606-0566

State Medical Academy, 8, Sheremetevsky Prospekt., 153012, Ivanovo, Russia

Aleksei V. Seleznev - Cand. of Med. Sci., Assistant Professor. https:// orcid.org/0000-0002-6321-8109

Doctor Glazov Ophthalmology Clinic, 7, Proletarskaya St.,143980, Balashikha, Russia

Hasmik Y. Zargaryan - Cand. of Med. Sci., ophthalmologist. https:// orcid.org/0000-0002-5965-2471

Contact information: Natalia A. Bakunina, nata-oko@mail.ru 